\title{
Analisis Makna Kematian: Sebuah Perspektif Konseptual Menurut Imam Ghazali
}

\author{
Zhila Jannati ${ }^{1}$ \\ (Fakultas Dakwah dan Komunikasi UIN Raden Fatah Palembang) \\ Email: zhila_jannati10@ radenfatah.ac.id \\ Muhammad Randicha Hamandia ${ }^{2}$ \\ (Fakultas Dakwah dan Komunikasi UIN Raden Fatah Palembang) \\ Email: mrandichahamandia_uin@radenfatah.ac.id
}

\begin{abstract}
Abstrak: Sejatinya, setiap yang hidup pasti akan mati. Kematian adalah sesuatu hal yang perlu dipahami sebagai sesuatu yang pasti akan terjadi agar manusia dapat menjalani kehidupan dengan baik sehingga dapat menghadapi kematian dengan penuh kesiapan. Penelitian ini bertujuan untuk memahami makna kematian menurut Imam Ghazali. Penelitian ini merupakan jenis penelitian studi literature atau kepustakaan (library research). Adapun teknik pengumpulan data yakni dengan menggunakan dokumentasi. Hasil penelitian menunjukkan bahwa (a) kematian merupakan suatu keadaan saat ruh mulai berpisah dari jasad, (b) keutamaan meningat kematian yakni dapat bertambahnya rasa takut manusia kepada Allah swt. sehingga dapat terus mempersiapkan diri untuk menyambut kematian, (c) sakaratul maut terbagi menjadi 3 fase bencana yakni rasa sakit yang begitu dahsyat ketika nyawa dicabut, menyaksikan malaikat maut yang dapat menciptakan rasa gentar dan takut dalam hati selama setahun, serta para pelaku maksiat yang akan menyaksikan neraka tempat mereka kembali dan merekapun sangat merasa ketakutan, serta (d) keadaan manusia dialam kubur yakni sendirian di tempat yang gelap, dipenuhi cacing, serta keadaan yang didapatkan manusia adalah sesuai dengan amal perbuatannya di dunia.
\end{abstract}

Kata kunci: Analisis kematian, Imam al-Ghazali

Abstract: In fact, every living thing will surely die. Death is something that needs to be understood as something that will definitely happen so that humans can live life well so they can face death with full readiness. This study aims to understand the meaning of death according to Imam Ghazali. This research is a type of research study literature or library (library research). The data collection technique is to use documentation. The results show that (a) death is a condition when the spirit begins to separate from the body, $(b)$ the virtue of remembering death is that it can increase human fear of Allah. so that they can continue to prepare themselves to welcome death, (c) death's sakaratul is divided into 3 phases of disaster namely the terrible pain when life is taken away, witnessing death angels that can create fear and fear in the heart for a year, and immoral practitioners who will witness the hell where they returned and they too felt very scared, and $(d)$ the condition of humans in the grave that is alone in a dark place, filled with worms, and the conditions that humans get are in accordance with the deeds of deeds in the world.

Keywords: Death analisys, Imam al-Ghazali 


\section{Pendahuluan}

Dunia, sebagai tempat persinggahan sementara manusia, nilainya lebih rendah dari sayap nyamuk. "Seandainya dunia ini di sisi Allah senilai harganya dengan sayap nyamuk niscaya Allah tidak akan memberi minum barang seteguk sekalipun kepada orang kafir" (HR. Tirmidzi). Dunia menyediakan berbagai hal dan manusia diuji seberapa mampu untuk menahan diri dari keinginan untuk mendapatkan segala hal tersebut. Kenikmatan dan kebahagiaan dari dunia ini bersifat semu dan sementara. Harta, jabatan, anak, istri, keluarga, dan lain sebagainya adalah ujian kenikmatan dunia. Apabila manusia lalai dari perintah Allah swt. dan mengabaikan akhirat, maka ia akan terlena dengan berbagai hal tersebut. Kelalaian dapat terjadi pada manusia yang terus menerus mengejar harta tanpa menghiraukan halal atau haramnya dari harta tersebut. Kelalaian juga terjadi apabila manusia terlalu mencintai anak, istri dan keluarga dimana adanya kebanggaan yang luar biasa terhadap anak, istri dan keluarga di hadapan manusia lain. Orang yang terlalu mencintai jabatan, akan sekuat tenaga supaya jabatan tersebut akan tetap dimilikinya atau bahkan menginginkan jabatan yang lebih tinggi lagi dengan cara apapun. Dengan hal tersebut, manusia tidak menyadari bahwa semua itu adalah titipan dari Allah swt. yang kapanpun Ia bisa mengambilnya tanpa segan.

Pemahaman bahwa manusia beranjak pergi dari dunia akan membawa manusia pada pemahaman bahwa tidak ada yang perlu dibanggakan dari dunia yang hina ini. “Sesungguhnya Nabi Shallallahu ,alaihi wa sallam berjalan melewati pasar sementara banyak orang berada di dekat Beliau Shallallahu ,,alaihi wa sallam . Beliau berjalan melewati bangkai anak kambing jantan yang kedua telinganya kecil. Sambil memegang telinganya Beliau Shallallahu ,,alaihi wa sallam bersabda, "Siapa diantara kalian yang berkenan membeli ini seharga satu dirham?" Orang-orang berkata, "Kami sama sekali tidak tertarik kepadanya. Apa yang bisa kami perbuat dengannya?” Beliau Shallallahu , alaihi wa sallam bersabda, “Apakah kalian mau jika ini menjadi milik kalian?” Orangorang berkata, "Demi Allâh, kalau anak kambing jantan ini hidup, pasti ia cacat, karena kedua telinganya kecil, apalagi ia telah mati?” Beliau Shallallahu „alaihi wa sallam bersabda: Demi Allâh, sungguh, dunia itu lebih hina bagi Allâh daripada bangkai anak kambing ini bagi kalian.” (HR. Muslim). Dari hadits tersebut dapat dipahami bahwa dunia itu lebih hina dari bangkai anak kambing. Padahal bangkai anak kambing berbau busuk dan tidak ada harganya. Dan ternyata dunia lebih tidak ada harganya dari pada hal tersebut. 
Kenikmatan dunia yang terus dikejar tidak akan menghasilkan apa-apa kecuali kepayahan, apabila tidak dilandasi dengan iman yang kokoh. Dunia ini akan ditinggalkan oleh manusia, karena manusia bukan makhluk abadi di dunia. Manusia hendaknya menjadikan dirinya sebagai seorang yang asing di dunia. Rasulullah saw. bersabda, "Jadilah engkau di dunia seolah-olah engkau orang asing atau orang yang lalu di jalan (HR. Bukhari, Ahmad, Tirmidzi dan Ibnu Majah). Asing dengan dunia berarti bukan tempat yang abadi untuk ditinggali dan asing juga berarti tidak terlalu mengenal dunia dan tidak terlalu menginginkannya. Sedangkan orang yang lalu di jalan artinya hanya sekedar lewat di jalan. Ia akan mengamati dan melihat kanan kiri ketika di berjalan agar tidak tertabrak sesuatu. Dengan pemahaman tersebut, maka manusia akan menyadari bahwa dunia hanya tempat yang di lalui untuk menuju ke tempat yang lebih abadi yakni akhirat.

Kematian merupakan gerbang awal manusia meninggalkan dunia dan menuju kampung akhirat. Setiap makhluk hidup pasti akan mengalami kematian, tak terkecuali manusia. Secara tiba-tiba, kematian akan datang pada waktu yang telah ditentukan oleh Allah swt. Waktu untuk setiap manusia dalam meninggalkan dunia berbeda-beda, ada yang cepat dan ada yang lambat. Akan tetapi, ketentuan tentang waktu kematian manusia tidak bisa dipercepat dan tidak bisa diperlambat. Malaikat maut akan datang menemui dan mencabut nyawa manusia dengan tepat waktu. Tidak ada manusia yang mengetahui kapan datangnya hari tersebut. Dari hari itu, manusia akan pergi meninggalkan keluarga, rekan, harta, dan jabatan yang dititipkan oleh Allah swt. kepadanya.

Sejatinya manusia perlu mengingat kematian karena dengan mengingat penghancur kenikmatan dunia, maka hati akan menjadi hati-hati dalam meniti kehidupan dunia agar tidak terjerumus pada kemaksiatan. Dari Ibnu „Umar, ia berkata, “Aku pernah bersama Rasulullah shallallahu ,,alaihi wa sallam, lalu seorang Anshor mendatangi beliau, ia memberi salam dan bertanya, "Wahai Rasulullah, mukmin manakah yang paling baik?” Beliau bersabda, "Yang paling baik akhlaknya." "Lalu mukmin manakah yang paling cerdas?", ia kembali bertanya. Beliau bersabda, "Yang paling banyak mengingat kematian dan yang paling baik dalam mempersiapkan diri untuk alam berikutnya, itulah mereka yang paling cerdas." (HR. Ibnu Majah). Orang yang paling cerdas adalah yang paling banyak mengingat kematian dan mempersiapkan untuk menghadapinya. Persiapan yang harus dilakukan oleh manusia adalah iman dan taqwa kepada Allah swt. Memperbanyak ibadah dan melakukan hal-hal yang bermanfaat dan berpahala adalah hal yang hendaknya dilakukan oleh manusia agar keranjang bekal dapat mencukupi sehingga ia akan siap dalam menemui kematian. Allah swt. telah berfirman. "Berbekallah, dan sesungguhnya sebaik-baik bekal adalah taqwa, dan bertaqwalah 
kepada-Ku hai orang-orang yang berakal". (Q.S. Al-Baqarah [2]: 197). Imam Hasan Al Basri berkata, "Jika engkau berada di sebuah pemakaman, hendaklah engkau merenungi keadaan, bagaimana air mata mereka bisa bercucuran, sementara lidahnya rapat tersumbat debu setelah di dunia berbicara begitu fasih dan menarik". ${ }^{1}$ Kematian itu benar-benar akan datang, maka hendaknya manusia terus memperbaiki diri, tidak menyia-yiakan waktu yang telah Allah swt. berikan di dunia. Manusia di dunia ini dapat diibaratkan sebagai orang yang sedang tidur, dan waktu bangunnya adalah ketika kematian datang. Ada banyak manusia yang lalai dari mengingat Allah swt. sehingga lalai mengerjakan sholat, puasa, zakat, berbakti kepada orang tua, mencintai sesama manusia, maupun melakukan ibadah-ibadah sunnah yang diajarkan oleh Rasulullah saw. Padahal semua itu adalah bekal yang akan menjadi teman nanti ketika mereka menemui ajalnya.

Manusia tidak dapat mengingat mati, tanpa adanya pemahaman tentang makna kematian. Makna kematian perlu dipahami sebagai suatu pengetahuan yang akan membawa manusia ke jalan yang benar karena tujuan manusia diciptakan bukan untuk bersenang-senang di muka bumi, akan tetapi adalah untuk beribadah kepada Allah swt. Manusia diciptakan untuk mengabdikan diri kepada Allah swt. dalam bentuk menjalankan segala perintahNya dan menjauhi segala laranganNya. Kebaikan adalah sebuah perlombaan yang hendaknya dilakukan oleh setiap manusia, bukan berlomba dalam kejahatan. Terus menerus melakukan ibadah adalah bentuk kecintaaan kepadaNya dan ketika kematian datang, kebahagiaan akan menaungi hati karena dengan kematian adalah waktu perjumpaan dengan Allah swt.

Akan tetapi, pada kenyataannya, masih terdapat manusia yang belum mengetahui makna kematian. Hal tersebut dapat disebabkan kurangnya usaha untuk mencari pengetahuan tentang hal tersebut atau juga tidak mau tahu tentang kematian karena pengetahuan tersebut dipandang sebagai sesuatu yang mengerikan. Manusia yang tidak mengetahui tentang hakikat kematian akan membayangkan bahwa kematian itu adalah sesuatu yang masih lama terjadi, apalagi usianya masih muda. Padahal syarat mati tidak harus tua, dan tidak harus sakit. Orang yang sehat, gagah, dan kuatpun apabila sudah tiba waktunya untuk meninggalkan dunia, maka pada saat itu juga ia akan mati.

Dari penjelasan di atas, dapat dikatakan bahwa pemahaman tentang makna kematian adalah sangat penting untuk dikaji sebagai pengetahuan yang sangat bermanfaat untuk hidup manusia. Penelitian yang berkenaan dengan kematian telah diteliti oleh peneliti-peneliti sebelumnya. Murtiningsih meneliti tentang "Hakikat Kematian Menurut Tinjauan Tasawuf".

\footnotetext{
${ }^{1}$ Murtiningsih. 2013. Hakikat Kematian Menurut Tinjauan Tasawuf. Intizar. Vol. 19. No. 2. Hal. 328
} 
Hasil penelitiannya yakni (1) kematian menurut kaum Sufi adalah orang hidup tetapi mati, yaitu mati rasa, tidak punya kepekaan terhadap situasi, mata memandang tetapi tidak melihat, kuping terbuka tetapi tidak mendengar, punya hidung tidak dapat mencium, (2) Cara yang dilakukan oleh kaum sufi untuk mengingat kematian, yaitu meyakini kematian sebagai suatu kepastian, (3) Istilah-istilah kematian dalam Al-qurean meliputi ajal, maut, atau wafat. ${ }^{2}$

Penelitian lainnya yakni penelitian yang dilakukan oleh Muzdalipah, dkk. mengenai "Makna Kematian pada Muslim Lanjut Usia". Hasil penelitian ini menunjukkan bahwa makna kematian pada lanjut usia adalah suatu peristiwa dan peringatan yang pasti diraskan oleh setiap manusia, subjek merasa susah dengan keadaan yang akan dialaminya ketika sakaratulmaut nanti dan khawatir meninggal dalam keadaan sue ul khotimah. Akan tetapi semua subjek berusaha menghindari rasa khawatir dan takut tersebut dengan bertakwa dan melakukan ibadah seperti sholat lima waktu, zikir, dan menjauhi segala larangan Allah swt. Faktor yang memengaruhi munculnya makna terhadap kematian adalah faktor pengalaman dan faktor lingkungan. ${ }^{3}$

Penelitian yang telah dijelaskan di atas berfokus pada makna kematian dalam pandangan Tasawuf dan kematian pada muslim lanjut usia. Adapun fokus pada penelitian ini adalah makna kematian menurut pserspektif dari Imam Ghazali. Dari penjelasan di atas, maka peneliti akan melakukan penelitian yang berjudul, "Memaknai Kematian: Sebuah Perspektif Konseptual Menurut Imam Ghazali”.

\section{Metode Penelitian}

Penelitian ini bertujuan untuk memahami makna kematian menurut Imam Ghazali. Penelitian ini merupakan jenis penelitian studi literatur atau kepustakaan (library research). Library research adalah jenis penelitian yang dilakukan dengan cara mengumpulkan data-data yang bersumber dari buku, jurnal, kitab, artikel, dan tulisantulisan tertentu. ${ }^{4}$ Menurut Arikunto, teknik pengumpulan data menggunakan dokumentasi, yaitu mencari data mengenai hal-hal atau variabel yang berupa catatan, transkip, buku, surat kabar,jurnal, majalah, prasasti, notulen rapat, agenda, dan sebagainya. ${ }^{5}$ Adapun buku yang menjadi sumber utama adalah buku karangan Imam Ghazali yang berjudul

\footnotetext{
${ }^{2}$ Ibid. Hal. 323-328

3 Muzdalipah Muzdalipah, Iredho Fani Reza dan Zaharuddin Zaharuddin, Makna Kematian pada Muslim Lanjut Usia, Jurnal Psikologi Islam dan Budaya, Vol. 1 No. 2, 2018, 131-142.

${ }^{4}$ Rusdin Pohan, Metodologi Penelitian Pendidikan, (Yogyakarta: Ar-RijalInstitute, 2007), Hal. 85.

${ }^{5}$ Suci Arischa, Analisis Beban Kerja Bidang Pengelolaan Sampah Dinas Lingkungan Hidup dan Kebersihan Kota Pekanbaru, JOM FISIP, Vol. 6 No.1, 2019, Hal.8/
} 
"Ringkasan Ihya" Ulumuddin" (diterjemahkan oleh Fudhailurrahman dan Aida Humaira dengan judul aslinya "Mukhtashar Ihyae Ulumuddin"). Analisis data penelitian menggunakan analisis isi (content analysis), yakni metode untuk mengumpulkan dan menganalisis muatan dari sebuah teks yang dapat berupa kata-kata, makna gambar, symbol, gagasan, tema, dan bermacam bentuk pesan yang dikomunikasikan. ${ }^{6}$

\section{Hasil dan Pembahasan}

\section{Analisis Makna Kematian menurut Ghazali}

Menurut Imam Ghazali, kematian merupakan kondisi ketika roh mulai berpisah dari badan, bukannya roh itu menghilang di mana semua berpisah dari badan, bukannya roh itu menghilang di mana semua kejadian itu mengandung pelajaran. Imam Ghazali menjelaskan pula bahwa terdapat manusia yang meninggal dengan khusnul khatimah seperti orang yang meninggal dalam keadaan syahid dan terdapat juga manusia yang meninggal dalam keadaan bersusah payah. manusia yang meninggal dalam keadaan syahid akan ditempatkan di sisi Allah swt. Hal ini dijelaskan dalam firman Allah swt. yang artinya, "Janganlah kamu mengira bahwa orang-orang yang gugur di jalan Allah itu mati, bahkan mereka itu hidup di sisi Tuhannya dengan mendapat rezeki” (Q.S Ali Imran: 169). ${ }^{7}$ Sedangkan manusia yang berlumuran dosa akan menghadapi kematian dengan sangat sulit. Rasulullah saw bersabda "Hai Fulan, hai fulan. Aku telah mendapatkan bahwa apa yang dulu telah dijanjikan Tuhanku kepadaku adalah benar. Apakah kalian juga mendapai bahwa apa yang telah dijanjikan oleh Tuhan kalian adalah benar?" Seseorang bertanya, "Ya Rasululah, apakah engkau berbicara dengan mereka padahal mereka telah mati?" Beliau menjawab, "Demi jiwaku yang berada di tanganNya, sesungguhnya mereka (yang telah meninggal) dapat mendengar ucapan ini dariku dan dari kalian, namun mereka tidak mampu untuk menajwabnya" (HR. Muslim). ${ }^{8}$

Kasih sayang Allah meliputi orang-orang yang beriman tak terkecuali pada saat mereka menghadapi kematian. Orang-orang Mukmin akan dihadiahkan surga dengan berbagai kenikmatan di dalamnya dikarenakan amal salih yang telah diperbuatnya. Abu

${ }^{6}$ Bahasa Arab AMA/MA/ SMK Muhammadiyah Kelas X Karya Drs. H. Abdul Quddus Zoher, M.Pd.I dan Syahbana Daulay, M.Ag. (Yogyakarta: Universitas Islam Negeri Sunan Kalijaga, 2014), Hal. 27.

${ }^{7}$ Lihat konsep tafsir dalam Razzaq, A., \& Haryono, A. (2017). Analisis Metode Tafsir Muhammad Ash-Shabuni dalam Kitab rawâiu’ al-Bayân. Wardah, 18(1), 48-59.

https://doi.org/https://doi.org/10.19109/wardah.v18i1.1432

${ }^{8}$ Ghazali, Ringkasan Ihya" Ulumuddin (Jakarta: SAHARA Publishers, 2015), Hal. 549. 
Ayyub al-Anshari meriwayatkan bahwa Rasulullah saw. bersabda, "Ketika orang Mukmin meninggal dunia, jiwanya disambut oleh para pemilik rahmat (penghuni surga) yang berada di sisi Allah, sebagaimana ia disambut manusia dengan penuh kasih sayang saat berada di dunia. Para pemilik rahmat itu berkata, "Biarkan dulu saudara kalian beristirahat. Sesungguhnya ia berada dalam kondisi yang sangat payah. Lalu mereka bertanya kepadanya,"Apa yang telah diperbuat oleh si Fulan? Apa yang telah diperbuat oleh si Fulanah? Apakah fulan telah menikah?” Jika mereka bertanya kepadanya tentang seseorang yang telah meninggal sebelumnya dan ia menjawab, "Ia sudah meninggal sebelumku,"maka mereka akan berkata, "Innalillahi wa innailaihi roji"un, ia telah ditempatkan di neraka hawiyah." 9

\section{Analisis Keutamaan Mengingat Kematian Menurut Ghazali}

Munawwir menjelaskan bahwa secara etimologi, kata "mati" diterjemahkan dari bahasa Arab mata-yamutu-mautan, yang artinya mati, menjadi tenang, menjadi using, dan tak berpenghuni. Sedangkan dalam terminologi agama, mati adalah keluarnya ruh dari jasad atas perintah Allah swt. ${ }^{10}$ Menurut Imam Ghazali menjelaskan bahwa terdapat manusia yang jarang sekali mengingat kematian namun ada juga manusia yang selalu mengingat kematian. Ketika mengingat kematian, dapat bertambah rasa takut manusia kepada Allah sehingga terus mempersiapkan diri untuk menghadapi datangnya hal tersebut. Selain itu, ada juga manusia yang ketika mengingat kematian, maka timbul kebencian pada kematian.

Manusia yang membenci kematian dapat disebabkan karena kecintaannya kepada dunia yang membuatnya terlena. Selain itu, kebencian terhadap kematian juga dapat disebabkan karena belum siapnya manusia untuk menghadapi datangnya kematian dikarenakan masih sedikitnya bekal yang dimilikinya. Kematian adalah keniscayaan yang pasti terjadi. Allah swt. berfiman, "Katakanlah, sesungguhnya kematian yang kamu lari daripadanya, maka sesungguhnya kematian itu akan menemui kamu." (QS. A1-Jumu ${ }^{\text {ee } a h ; ~}$ 62: 8). Mengingat mati hendaknya dilakukan oleh setiap manusia. Karena dengan mengingat mati akan membuat individu sadar bahwa kehidupan di dunia ini hanya sementara dan segala perbuatan akan dipertanggungjawabkan di hadapan Allah swt.

\footnotetext{
${ }^{9} \mathrm{Ibid}$, Hal. 550.

${ }^{10}$ Abdul Karim, Makna Kematian dalam Perspektif Tasawuf, ESOTERIK. Vol.1 No.1, 2015, Hal. 26
} 
Rasulullah saw. Bersabda, "Perbanyaklah mengingat penghancur segala kenikmatan (yaitu kematian. (HR. Ibnu Majah). Rasulullah saw. menyuruh setiap manusia untuk memperbanyak waktu untuk mengingat penghancur segala kenikmatan yang ada di dunia, karena kenikmatan yang sejati hanya ada di akhirat, kampung halaman terakhir manusia.

Ada manusia yang memandang kematian itu sesuatu yang nanti-nanti dan menyenangkan, ada manusia yang memandang kematian itu sesuatu yang mengerikan, dan ada pula manusia yang memandang kematian itu adalah sesuatu yang biasa-biasa saja. Bagi orang mukmin yang telah banyak bekalnya dengan telah melakukan apa yang diperintahkan oleh Allah swt. dan menjauhi segala larangannya, maka kematian merupakan hal yang ditunggu-tunggu untuk mendapatkan hasil dari jerih payahnya di dunia. Rasulullah saw. Bersabda, "Hadiah orang Mukmin adalah kematiannya (HR. AlHakim). Orang-orang beriman menganggap kematian sebagai gerbang untuk mencapai kebahagiaan yang abadi.

Rasulullah saw. Bersabda, "Cukuplah kematian menjadi sebuah nasehat dan peringatan. Dalam hal ini, bukan manusia yang menasehati sesamanya, akan tetapi kematianlah yang menjadi nasehat yang dapat menjadikan seseorang menjadi manusia yang dicintai oleh Allah swt. "Suatu hari Rasulullah saw. keluar dari masjid dan beliau mendapatkan sekelompok orang sedang berbicara dan tertawa gembira. Lalu Rasulullah saw. Berkata kepada mereka, "Ingatlah mati, demi jiwaku yang berada ditanganNya, jika kalian mengetahui seperti apa yang aku ketahui tentang kematian, pastilah kalian akan lebih banyak menangis daripada tertawa" (HR. Al-Baihaqi). Dalam hadits tersebut dikatakan bahwa manusia jika manusia mengetahui bagaimana dahsyatnya kematian, tentu setiap orang akan jarang tertawa karena takutnya pada sakaratul maut apabila tidak ada bekal yang banyak untuk menyambutnya.

\section{Analisis Sakaratul Maut Menurut Ghazali}

Imam Ghazali mengemukakan bahwa kematian merupakan satu-satunya perkara yang menakutkan bagi manusia. Perkara tersebut tidak diketahui kapan datangnya. Luqman pernah berkata kepada anaknya, "Ada perkara yang tidak kamu ketahui kapan ia akan datang kepadamu. Oleh karenanya, bersiaplah sebelum ia datang mengejutkanmu. Anehnya, ketika seseorang mengetahui bahwa sekompi tentara akan datang kepadanya untuk memukulnya dengan lima pukulan, ia akan merasa was-was dan mengkhawatirkan nasibnya sepanjang 
waktu. Namun ketika yang akan datang adalah malaikat maut, bagaimana ia tidak merasa was-was akan nasib dirinya?"11

Terdapat tiga fase bencana yang dihadapi manusia ketika sakarakut maut datang menjemput yakni sebagai berikut:

Bencana pertama yakni rasa sakit yang begitu dahsyat ketika nyawa dicabut rasa sakit ketika menghadapi kematian telah jelaskan oleh Rasulullah saw. Diriwayatkan dari al-Hasan, "Suatu hari Nabi Muhammad saw. Bercerita tentang kematian, kesulitan dan rasa sakitnya. Lalu beliau berkata," Rasa sakitnya kira-kira sama dengan tiga ratus kali tusukan pedang." Imam Ghazali menganalogikan bahwa rasa sakit ketika sakaratul maut tidak hanya dirasakan ruh, akan tetapi dirasakan oleh sekujur tubuh dengan sakit yang luar biasa yang belum pernah dirasakan sebelumnya. Suara orang yang mengalami sakaratul maut akan tersendat-sendat, lidah menjadi kaku, kemampuan akal menjadi lumpuh, seluruh organ tubuh menjadi sangat lemah, serta dada mulai berubah warna dan terbujur kaku. Ketika ruh mulai dicabut dari seluruh persendian, semua anggota tubuh akan mati perlahan. Pertama-tama kaki akan menjadi dingin, kemudian betis dan paha akan merasakan hal yang sama. Tubuh akan mengalami sakit yang luar biasa sampai ke tenggorokan. Dan saat hal itu terjadi, pandangan terhadap dunia akan terputus dan pintu tobat akan tertutup. Rasulullah saw. Bersabda, "Tobat seorang hamba masih akan diterima selagi nyawanya belum sampai ke tenggorokan.”(HR. At-Tirmidzi). ${ }^{12}$

Bencana kedua yakni menyaksikan malaikat maut yang dapat menciptakan rasa gentar dan takut dalam hati selama setahun Imam Ghazali menjelaskan mengenai dua keadaan manusia saat bertemu dengan malaikat maut. Yang pertama adalah keadaan banyak melakukan dosa, maka manusia tersebut akan melihat malaikat maut dengan bentuk yang menakutkan. Diriwayatkan bahwasanya Nabi Ibrahim pernah berkata kepada malaikat maut, "Bisakan engkau memperlihatkan bentukmu kepadaku saat engkau mencabut roh pendosa?" Malaikat menjawab, "Engkau tidak akan mampu menyaksikannya, tapi baiklah. Sekarang berpalinglah dariku." Ketikan Nabi Ibrahim berpaling, ia melihat seorang laki-laki berambut hitam tegak berbau busuk dan berpakaian hita. Dari mulut dan lubang hidungnya keluar asap dan api yang berkobar-kobar sehingga membuat Nabi Ibrahim jatuh pingsan. Ketika ia sadar, malaikat maut sudah kembali ke wujud semula. Kemudian Nabi Ibrahim berkata, "Wahai

${ }^{11}$ Ghazali, Ringkasan Ihya" Ulumuddin (Jakarta: SAHARA Publishers, 2015), Hal. 522-523

12 Ghazali, Ringkasan Ihya" Ulumuddin (Jakarta: SAHARA Publishers, 2015), Hal. 527-528. 
malaikat maut, bagaimana kondisi orang yang banyak dosa saat menemui ajalnya, sungguh ia akan sangat ketakutan menyaksikan wujudmu.

Adapun yang kedua, adalah keadaan orang mukmin yang taat kepada Allah swt. di mana ketika menemui malaikat maut ia akan melihat malaikat maut dengan penampilan yang sangat baik. Dalam suatu riwayat diceritakan bahwa "Pada suatu hari, saat Nabi Ibrahim kembali ke tempat peribadatannya, tiba-tiba ia melihat seorang lelaki berada di dalam rumahnya, maka ia pun bertanya, "Siapa yang telah membawamu masuk ke rumahku?" Orang itu menjawab, "Yang membawaku masuk adalah Zat Yang Berkuasa atas diriku dan dirimu." Nabi Ibrahim bertanya, Apakah engkau salah satu malaikat? Ia menjawab, "Ya, aku adalah malaikat pencabut nyawa." Nabi Ibrahim lantas bertanya, "Apakah engkau dapat memperlihatkan wujudmu saat engkau mencabut nyawa orang Mukmin?" Malaikat itu menjawab, "Ya". Lalu Nabi Ibrahim berpaling, lalu membalikkan tubuhnya kembali, tiba-tiba ia menyaksikan seorang pemuda berpenampilan rapi, bersih, wajahnya tampan dan harum baunya. Setelah itu Nabi Ibrahim berkata, "Jika saat orang Mukmin menemui ajalnya, ia melihat wujud seperti ini, sungguh ia akan merasa senang.

Imam Ghazali (2015: 532) juga menambahkan bahwa menyaksikan dua malaikat pencatat amal adalah yang akan dialami oleh orang yang menghadapi kematian. Wahab bin Munabbih berkata, "Telah sampai berita kepada kami bahwa tidak ada orang yang meninggal dunia, kecuali ia diperlihatkan dua malaikat pencatat amal. Jika ia orang yang taat, maka kedua malaikat itu akan berkata, „Allah swt. akan member pahala kebaikan kepadamu. Berapa banyak majelis kebajikan yang kamu ikuti, atau amal baik yang kamu lakukan yang dihadapkan kepada kami. “e Jika orang itu bergelimang dosa, maka kedua malaikat itu akan berkata, „Allah swt. tidak akan memberi kebaikan kepadamu. Berapa banyak omongan keji dan kotor yang engkau perdengarkan kepada kami.e Itulah gambaran kedua malaikat yang akan disaksikan oleh orang yang mati." 13

Bencana yang ketiga adalah para pelaku maksiat yang akan menyaksikan neraka tempat mereka kembali dan merekapun sangat merasa ketakutan. Imam Ghazali, pada saat sakaratul maut, maka manusia akan mengetahui kemana tempat yang akan ia diami selanjutnya. Pilihannya ada dua, yakni di surga atau di neraka. Rasulullah saw. Bersabda, "Ruh salah satu dari kalian tidak akan keluar dari dunia hingga ia mengetahui kemana arah

${ }^{13}$ Ibid, Hal. 528-530. 
perjalanannya, dan hingga ia melihat tempat tinggalnya, di surga atau di neraka. " (HR. Bukhari dan HR. Muslim). ${ }^{14}$

\section{Analisis Keadaan Manusia di Alam Kubur Menurut Ghazali}

Menjadi suatu keharusan bagi manusia agar selalu mengingat mati, tidak terlena dengan kemewahan dan kenikmatan yang ada di dunia. Sejatinya, manusia harus mengetahui bahwa rumahnya setelah kematian adalah gelap dan dipenuhi cacing. Manusia akan tinggal di dalamnya seorang diri tanpa satupun teman seperti halnya ketika hidup di dunia. Rasulullah saw. Bersabda, "Ketika mayit baru saja diletakkan dalam liang lahat, alam kubur itu akan berkata, „Wahai manusia, celaka kamu. Apa yang telah memperdayamu (sehingga berbuat durhaka) terhadapku? Sungguh, aku adalah rumah cobaan, tempat yang gelap, ruang isolasi dan sarang cacing. Apa yang telah memperdayamu hingga engkau melupakanku saat sedang berjalan melintasiku ketika mengantar jenazah? " Jika yang meninggal adalah orang baik, maka amal baiknya akan mencarinya dan ia akan menjawab pertanyaan alam kubur dengan berkata, "Tahukah engkau jika ia telah menyeru kepada kebaikan dan mencegah kemungkaran? ${ }^{e e}$ Alam kubur

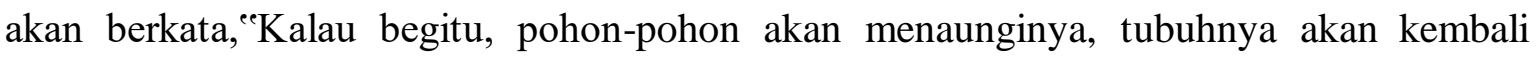
menjadi cahaya dan ruhnya akan naik ke sisi Allah swt."(HR. Hindi).

Dari hadits di atas, dapat dikatakan bahwa alam kubur sangat berbeda dengan alam dunia. Namun, sedikit sekali manusia yang memahami hal tersebut sehingga ketika di dunia, sebagian manusia melupakan kubur yang akan menjadi rumah masa depannya. Ketika menghadapi kematian, dan manusia dimakamkan oleh sanak saudaranya. Kemudian, sanak saudaranya itupun akan meninggalkannya seorang diri. Di tempat yang gelap gulita, manusia akan mempertanggungjawabkan apa yang telah dikerjakan oleh mata, hati, telinga, tangan, kaki dan seluruh anggota tubuhnya di dunia tanpa satupun yang terlewatkan. Hanya ada amal yang akan menemani setelah kematian.

Adapun kondisi setiap manusia di dalam kubur tergantung dengan apa yang telah dikerjakannya ketika di dunia. Orang Mukmin dan orang kafir tentu berbeda kondisinya ketika di dalam kubur. Rasulullah saw bersabda, "Dalam kuburnya, orang Mukmin laksana berada di sebuah taman hijau yang ditopang oleh tujuh puluh tiang dan memancarkan sinar terang-benderang hingga laksana cahaya bulan purnama." Nabi saw. Bertanya, "Kalian

14 Ibid, Hal. 530-532 
tahu, kepada siapa ayat, "Sesungguhnya baginya penghidupan yang sempit." (QS. Thaha: 124) ${ }^{15}$ ditujukan?" Para sahabat menjawab, “Alah dan Rasul-Nya lebih mengetahui." Nabi berkata, "Untuk orang kafir yang diazab dalam kuburnya. Dalam kubur, ia akan didatangi 99 ekor naga. Kalian tahu tentang naga itu? Naga itu adalah 99 ekor ular, di mana setiap ular memiliki 70 kepala. Ular-ular tersebut mencakar, menyengat dan menghembus tubuhnya hingga hari kiamat." (HR. al-Hatsami). Selain itu, Aisyah pernah berkata, "Dalam kubur terdapat goncangan, jika ada seseorang yang selamat dari goncangan tersebut, niscaya Saee ad bin Muadz juga akan selamat. (Hr. Ibnu Hibban).

\section{Penutup}

Dari hasil penelitian di atas dapat disimpulkan bahwa (a) kematian merupakan suatu keadaan saat ruh mulai berpisah dari jasad, (b) keutamaan meningat kematian yakni dapat bertambahnya rasa takut manusia kepada Allah swt. sehingga dapat terus mempersiapkan diri untuk menyambut kematian, (c) sakaratul maut terbagi menjadi 3 fase bencana yakni rasa sakit yang begitu dahsyat ketika nyawa dicabut, menyaksikan malaikat maut yang dapat menciptakan rasa gentar dan takut dalam hati selama setahun, serta para pelaku maksiat yang akan menyaksikan neraka tempat mereka kembali dan merekapun sangat merasa ketakutan, serta (d) keadaan manusia dialam kubur yakni sendirian di tempat yang gelap, dipenuhi cacing, serta apa yang didapatkan manusia adalah sesuai dengan amal perbuatannya di dunia.

\section{Daftar Pustaka}

Arischa, Suci. (2019). Analisis Beban Kerja Bidang Pengelolaan Sampah Dinas Lingkungan Hidup dan Kebersihan Kota Pekanbaru. JOM FISIP. 6 (1). 8.

Al-Ghazali, Imam. (2015). Ringkasan Ihya" Ulumuddin. Jakarta: SAHARA Publishers.

Hidayati, Nur Laili. (2014). Analisis Content Buku Ta’lim al-Lughah Al-'Arabiyyah.

Karim, Abdul. (2015). Makna Kematian dalam Perspektif Tasawuf. ESOTERIK. 1.(1). 21-46.

${ }^{15}$ Lihat pembahasan tafsir dalam Razzaq, A., \& Perkasa, J. (2019). Penafsiran Ayat-Ayat Jihad Dalam Kitab Al-Qur'an Al-'Adzim Karya Ibnu Katsir. Wardah,20(1), 71-84. Retrieved from http://jurnal.radenfatah.ac.id/index.php/warda/article/view/3621. 
Muzdalipah; Reza, Iredho Fani; Zaharuddin. (2018). Makna Kematian pada Muslim Lanjut Usia. Jurnal Psikologi Islam dan Budaya. 1 (2). 131-142.

Murtiningsih. (2013). Hakikat Kematian Menurut Tinjauan Tasawuf. Intizar. 19 (2). 323328.

Pohan, Rusdin. (2007). Metodologi Penelitian Pendidikan. Yogyakarta: Ar-Rijal Institute.

Razzaq, A., \& Haryono, A. (2017). Analisis Metode Tafsir Muhammad Ash-Shabuni dalam Kitab rawâiu' al-Bayân. Wardah, 18(1), 48-59.

http://jurnal.radenfatah.ac.id/index.php/warda/article/view/1432. https://doi.org/https://doi.org/10.19109/wardah.v18i1.1432.

Razzaq, A., \& Perkasa, J. (2019). Penafsiran Ayat-Ayat Jihad Dalam Kitab Al-Qur'an Al'Adzim Karya Ibnu Katsir. Wardah, 20(1), 71-84. Retrieved from http://jurnal.radenfatah.ac.id/index.php/warda/article/view/3621.

Zoher, Abdul Quddus; Daulay, Syahbana (2014). Pendidikan Bahasa Arab AMA/MA/ SMK Muhammadiyah Kelas X. Skripsi. Yogyakarta: Universitas Islam Negeri Sunan Kalijaga. 